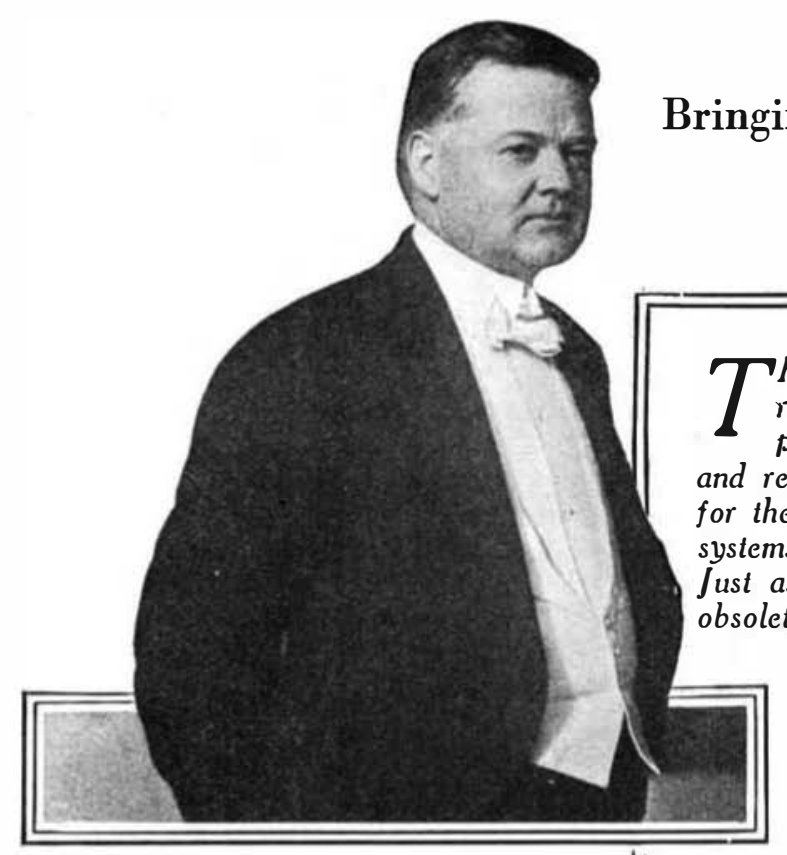

TO establish authority by which to pro1 vide order, instead of anarchy, in the ether, is the purpose of the Radio Bill now before Congress. The bill expresses the recommendations of the technical, amateur and legal committees of the Radio Conference called at the request of the President on February 27. It looks to procuring for the largest number the benefits to be derived from systematized use of the ether: establishes conclusively the legal right of the Bureau of Navigation to grant, and to revolse, operator and station licenses; provides for the collection of fees with which to maintain more adequately the work of inspection, promises a fairer and more orderly allocation of available wave bands, and, to make Federal regulation continuously effective, establishes an advisory committee composed of representatives of the departments and the public, to assist the Department of Commerce to provide, concurrently, without the delay attendant on new legislation, for unexpected changes in the science, and, notably, for developments in the use of the radio telephone.

Existing authority, which is clearly inadequate, is based on the act approved August 13, 1912, and on the International Convention of the same year, before the advent of the radio-phone, which for practical purposes was the product of the war and the years immediately following the war. Since 1912 the radio-phone, in the point of view of the public, has come to have larger importance even than the radio telegraph, yet the only reference to the phone in the original legislation is in Section 6: "The expression 'radio communication' as used in this act mean any system of electrical communication by telegraphy or telephony without the aid of any wire connecting the points from and at which the radiograms, signals or other communications are sent or received." Moreover, while the use of the radio-phone has spread with incredible rapidity so that it is now estimated there are fully a million and one-half of radiophone receiving sets in the United States, the use of wireless telegraphy has also greatly been extended. The resulting confusion has operated to discourage progress, temporarily, in a field which has already attracted a larger range of technical, as well as amateur, abilities, than any scientific development, heretofore

The relation of the many stations owned by the various departments of the Government to private and commercial stations has also presented a perplexing problem. The military and naval branches of the Government in particular have contended vigorously and with justification that their stations ought not to be subjected to civilian control. Accordingly the bill for the first time differentiates between

\section{Policing the Ether}

Bringing About Order Out of Disorder Through the Radio Bill Now Before Congress

By Hon. Herbert Hoover

Secretary of Commerce

HE ether, or whatever may be the medium which carries the radio waves from the transmitter to the receiving set, must be policed. Ever since 1912 there have been in force certain lanss and regulations, as well as a system of operators' and station licenses, for the use of the ether; and these laws and regulations and licensing systems served admirably until the advent of radio-phone broadcasting. ust as the rules of the road, such as they were, became hopelessly obsolete and inadequate when the automobile came into existence, so have the lans and regulations and licenses of 1912 become antequated and obsolete in the face of the radio-phone broadcasting activities throughout the nation. Then again, the automobile was not an overnight development: it required years of slow and painstaking progress before it became an important factor in our transportation scheme. The radiophone, on the other hand, nas developed into an everyday, nation-pide convenience overnight.

Hence the radio laws which were formulated when the radio telephone was little more than a laboratory experiment, have proved absolutely useless and even detrimental in the present radio traffic tangle. But the Government, represented by the Department of Commerce, in charge of radio regulations, has been quick to realize the inadequacy of the present radio lans, and has devoted no little time and effort, aided by the various groups interested in radio communication, toward the formulating of new and more suitable laws and regulations. And no one, to ke sure is better prepared to speak on the subject than Hon. Herbert Hoover, Secretary of Commerce, who addresses you through these columns. - THE EDITOR.

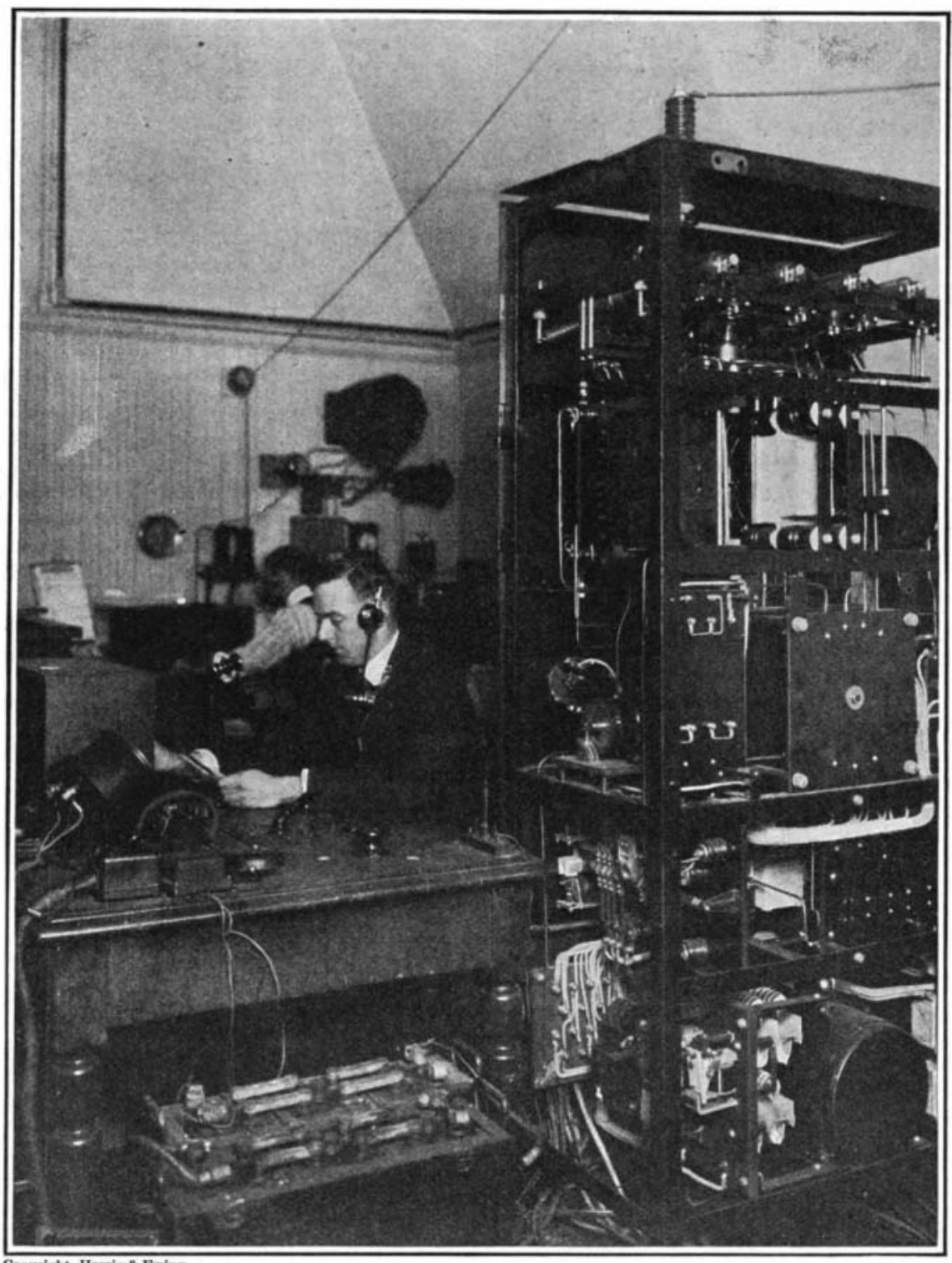

Radio-phone broadcasting station recently installed in the United States Post Office Department Building at Washington, D. C., for the broadcasting of Governmental bulletins and talks governmental and military, or naval, uses of radio. It provides that the President shall allocate wave lengths which Government stations shall use for strictly governmental purposes, while all other governmental broadcasting shall be subject to the same central regulation and control as is maintained for private transmitting stations.

The bill also amends the provision in the basic law to the effect that the wave lengths, 600 to 1600 meters, shall be reserved, in accordance with the International Convention, for military use. The conference was of the opinion that all wave lengths in this large range not essential to military use, should be made available to the public. Accordingly, the present Radio Bill proposes that this reservation be removed. In other words, when the Government's essential requirement will have been determined by the President a much larger range for broadcasting will be available to the Department of Commerce for allocation to the best possible advantage.

Amateurs can then be encouraged in a larger way. Newspapers, more than forty of which are now broadcasting, can be afforded a separate band. Commercial broadcasting can be stabilized in a large plan. Interference will be diminished And the general result of the proposed legislation must, therefore, recommend itself to the industry and the public, generally.

\section{The Moss Rose}

THE origin of the moss rose is the sub1 ject of a paper by Major Hurst and Miss M. S. G. Breeze in the recent issue of the Journal of the Royal Horticultural Society. The moss rose differs from the cabbage rose only in the much oreater development and branching character of the glands on petioles and sepals and the branching of the latter. The cabbage rose has been in cultivation for more than 2000 years, and the earliest record of the moss rose is from Carcassonne, in southern France, where it probably originated as a bud-mutation from the cabbage rose at least as early as 1696. 'The mossy character has since arisen independently from two other varieties of the cabbage rose.

Thus, in 1775 the Unique Rose appeared in a garden in the eastern counties as a tinged-white variety, and in turn gave rise to the "Unique Moss" through a budmutation in France about 1843. The Rose de Meaux is a miniature variety of the cabbage rose which may date from about 1637. A moss-mutation appeared from this in the west of England in 1801. Both the moss and cabbage rose are sterile, and there is little doubt that all these derivatives arose from the old cabbage rose as bud-mutations. The records show that at least seven bud-reversions from the moss rose to the cabbage rose occurred in the period between 1805 and 1873 . In the half-century following 1788 seventeen varieties of the moss rose appeared, one of which was single and fertile and extensively used in crossing. Twelve of these bud-mutations are parallel to corresponding earlier variations in the old cabbage rose Bud-mutation is therefore a frequent phenomenon in Rosa Centifolia under cultivation, and there is, as the authors suggest, a direct connection between this condition and the sterility. The evidence indicates that the mossy character is in all probability a simple Mendelian dominant. 